\title{
Exploration in Construction Quality Evaluation Model for Chinese Universities High Level Sports Teams and Application Analysis of "Fuzzy Comprehensive Evaluation Method"
}

\author{
Junfang Wei \\ Department of Sports and Arts, Zhejiang University,Hangzhou, Zhejiang, China
}

\begin{abstract}
With the the advent of the high-tech era in the new century, "the main cause of sports", that are association with human life, health and survival, are beyond all dispute into the hall of "the modern science and technology" and become essential material and spiritual wealth for people all over the world.

As the business of "School Sports" is booming, our colleges and universities in the care and support of the party and the state construct high-level sports teams in colleges conditional approved by the Ministry of Education in the late 1980s and early 1990s. So far, the success were considerable and worthy of affirmative. But in the 21st century, there are a considerable part of universities and sports teams establishing a high level, that show a continuously booming momentum and is worth gratifying.

By reviewing the history and future prospects, in summing up the successful experience, it was also not difficult to find that a comprehensive evaluation of the construction of high-level college sports teams lack a scientific quality that is reasonable and appropriate, accurate and practical unified approach, and then achieve to the improvement of quality standards. In view of this, follow the the principle of the "needs and possibilities", we launched the international and domestic generic formula of "Fuzzy" fuzzy evaluation, that is helpful for the construction of formulas high level sports teams in colleges and universities to quality comprehensive evaluation and rational choice, and exceed and continue to move forward for the training of university sport a better way to open up scien.
\end{abstract}

Keywords: Chinese universities; high level sports team; Fuzzy fuzzy comprehensive evaluation method

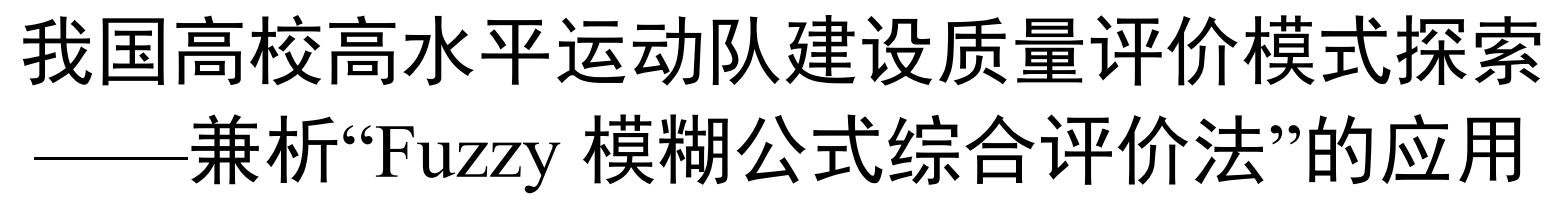

\author{
韦俊芳 \\ 浙江大学公共体育与艺术部，杭州，浙江，中国
}

摘 要 随着新世纪高科技信息时代的到来, “体育”这项关系人类生命健康、生存发展的重要事业也无可争辩地步入“现代科学技 术”的殿堂，成为全世界人民必需的精神与物质的财富。

另又随着“学校体育”事业的蓬勃发展, 我国高校在党和国家的关怀支持下, 于 20 世纪 80 年代末与 90 年代初, 由教育部批准在有 条件的高校建设高水平运动队。迄今成效可观、值得肯定。但进入 21 世纪以来, 又有相当部分高校建立和正在筹建高水平运动队, 呈 现出不断兴旺的势头，也是值得可喜可贺的。

通过回顾历史, 展望未来, 在总结成功经验的同时, 又不难发现对我国高校高水平运动队建设的质量综合评价尚缺乏一个科学量 化的即合理又恰当、既准确又实用的统一方法, 从而能达到不断提高办队质量标准目的。有鉴如此，在“需要与可能”的原则指导下， 推出当今国际国内通用的“Fuzzy”模糊公式评价法来对建设高水平运动队的高校进行办队质量综合评判、合理取舍、分析其所达到的层 次水平，以便扬长避短、不断前进，为我国高校体育运动训练开辟一个更加美好的科学发展之路。

关键词 我国高校, 高水平运动队, Fuzzy 模糊公式综合评价法 


\section{1. 前言}

“学校体育”是多功能、全方位综合治理学校的一项不 可缺少的重要一环, 而“体育训练”又是“学校体育”的一个 必要组成部分, 它和教学、群体、训练、竞赛、管理、科 研共同承担起了完成“学校体育”全面贯彻“健康第一”宗旨 的任务。

为了更好地进行“体育训练”在有条件的高校建设高水 平运动队又势在必行。我国目前由教育部批准办高水平运 动队的相关高校有逾百所。多年来, 培养了不少优秀运动 员, 在国际国内大学生比赛中取得了不少荣誉, 为我国体 育运动的发展及“学校体育” 的进步贡献了力量, 这是值得 肯定的。

但综观我国高校高水平运动队建设的历程, 不难发现: 在总结成功经验的基础上，对所具备高水平运动队资格的 院校, 进行全面分析评价仍停留在经验定性的层面, 皆无 法升华到科学定量的高度来评价彼此的优劣, 甚至精确地 将有关高校按质量水平依照评选得分高低排列顺序, 这样 无论是表彰先进、警示后进, 进行“优胜劣汰”就可以切实 做到有据可查、有法可依了, 无疑对我国高校建设高水平 运动队保质保量及持续健康发展是十分有利的。

实施对我国高校高水平运动队的科学评价是我国“学 校体育” 在新时期教育改革与创新中的一种必然的需要, 故 我们必须提供这样的可能, 只有这种“需要与可能”相结合, 才能营造出“学校体育”的一种崭新的发展前景。

当今, 国际国内众多高校皆十分重视“学校体育”的科 学评价工作, 均投入了大量的人力、物力、财力和时间从 事这项系统工程的运作。针对目前我国高校的紧迫之需, 本文拟介绍其中最简单易行且又科学合理的“Fuzzy 模糊公 式综合评价法”来加以应用。

\section{2. “Fuzzy 模糊公式综合评价法”方法简介}

该方法是“模糊教学”的一个实用分支, “模糊教学”是 指研究和处理处于模糊状态 (现象) 的人和物的一种应用 教学。它是 20 世纪 60 年代以后发展起来的, 首先由美国
控制论专家, 加利福尼亚大学 L.A.Zaden（查德）教授提 出, 从此为“模糊教学”的发展奠定了理论基础。“模糊”二 字来自英语“Fuzzy”一词。

高校高水平运动队建设是一个典型的系统工程, 它涉 及的因素是多层次、多方面的, 且具有众多的复杂性和模 糊性, 为此就相应地引进“Fuzzy 公式法”来对不可定量的 处于模糊状态 (现象) 的各因素加以定量的分析研究是十 分可取的 (这是当今高科技社会一种科学量化的需要)。

\section{3. 实例计算与分析}

3.1 评价实例

某高校田径代表队 (国家教育部批准布点), 为参评体 育运动队建设一年一度的综合检查评估, 其评价指标详见 (图 1)。


(图 1)

将 (图 1) 各级指标系列转换成“FUZZY 公式法”之评价表中, 见（表 1) 
表 $\mathrm{A}$ 高等学校建立高水平运动队质量综合评价表

\begin{tabular}{|c|c|c|c|c|c|c|c|c|c|c|c|c|}
\hline \multirow{3}{*}{\multicolumn{2}{|c|}{ 评价指标 }} & \multicolumn{2}{|c|}{ 领导重视程度 } & \multicolumn{2}{|c|}{ 组织机构设置 } & \multicolumn{3}{|c|}{ 科学规范培训 } & \multicolumn{3}{|c|}{ 成绩效益反映 } & \multirow{3}{*}{ 隶属度 } \\
\hline & & 1 & 2 & 3 & 4 & 5 & 6 & 7 & 8 & 9 & 10 & \\
\hline & & 是否校领导主管 & $\begin{array}{c}\text { 全方位支持情 } \\
\text { 况 }\end{array}$ & $\begin{array}{c}\text { 建队严谨程 } \\
\text { 度 }\end{array}$ & $\begin{array}{c}\text { 规章制度完 } \\
\text { 整如何 }\end{array}$ & 科学选材 & $\begin{array}{l}\text { 科学 } \\
\text { 训练 }\end{array}$ & $\begin{array}{l}\text { 科学 } \\
\text { 管理 }\end{array}$ & $\begin{array}{c}\text { 思想品德 } \\
\text { 教育 }\end{array}$ & 文化学习 & 竞技水平 & \\
\hline \multirow{5}{*}{$\begin{array}{l}\text { 评 } \\
\text { 语 } \\
\text { 等 } \\
\text { 级 }\end{array}$} & 上 & $\begin{array}{l}\text { 校长或党委书记 } \\
\text { 主管; 定期召集 } \\
\text { 会议, 检查落实 } \\
\text { 各项工作及时解 } \\
\text { 决各种问题 }\end{array}$ & $\begin{array}{c}\text { 能在建设高水 } \\
\text { 平队理念及硬 } \\
\text { 软件建设经费 } \\
\text { 有关政策上全 } \\
\text { 力支持 }\end{array}$ & $\begin{array}{c}\text { 建队严谨, 责 } \\
\text { 任分工明确 } \\
\text { 到位 }\end{array}$ & $\begin{array}{c}\text { 具有系列规 } \\
\text { 章制度、规范 } \\
\text { 条例, 管理有 } \\
\text { 序 }\end{array}$ & \begin{tabular}{|c} 
有科学的手 \\
段方法, 标准 \\
合理、实用
\end{tabular} & $\begin{array}{c}\text { 有科学手段、 } \\
\text { 方法、措施, } \\
\text { 训练方案实施 } \\
\text { 很严谨 }\end{array}$ & $\begin{array}{c}\text { 有科学手段、 } \\
\text { 方法、措施, } \\
\text { 效果很好 }\end{array}$ & $\begin{array}{l}\text { 很切合实 } \\
\text { 际并具有 } \\
\text { 相当实效 }\end{array}$ & \begin{tabular}{|c|} 
有较高学 \\
习效率, 能 \\
很好完成 \\
学习任务
\end{tabular} & $\begin{array}{l}\text { 能进入全国高 } \\
\text { 校比赛前三 } \\
\text { 名, 能代表学 } \\
\text { 校乃至国家出 } \\
\text { 访并获好成绩 }\end{array}$ & $\begin{array}{c}0.95 \\
(0.9-1)\end{array}$ \\
\hline & 中上 & $\begin{array}{c}\text { 有校领导分管; } \\
\text { 有专门会议制 } \\
\text { 度; 能解决主要 } \\
\text { 问题 }\end{array}$ & $\begin{array}{c}\text { 能加以较好支 } \\
\text { 持 }\end{array}$ & $\begin{array}{c}\text { 责任分工较 } \\
\text { 好 }\end{array}$ & 比较完整 & $\begin{array}{c}\text { 比较合理、实 } \\
\text { 用 }\end{array}$ & $\begin{array}{c}\text { 实施严谨、计 } \\
\text { 划较强 }\end{array}$ & 效果较好 & $\begin{array}{c}\text { 有一定实 } \\
\text { 效 }\end{array}$ & $\begin{array}{c}\text { 能完成学 } \\
\text { 习任务 }\end{array}$ & $\begin{array}{c}\text { 全国比赛前八 } \\
\text { 名, 全省前二 } \\
\text { 名并代表学校 } \\
\text { 出访 }\end{array}$ & $\begin{array}{c}0.75 \\
(0.7-0.8)\end{array}$ \\
\hline & 中 & $\begin{array}{l}\text { 有校领导代管; } \\
\text { 不定期会议; 只 } \\
\text { 能解决部分问题 }\end{array}$ & 能一般支持 & $\begin{array}{c}\text { 责任分工一 } \\
\text { 般 }\end{array}$ & 一般具有 & 一般 & $\begin{array}{l}\text { 实施 } \\
\text { 一般 }\end{array}$ & $\begin{array}{l}\text { 效果 } \\
\text { 一般 }\end{array}$ & 一般 & $\begin{array}{c}\text { 学习效率 } \\
\text { 一般 }\end{array}$ & $\begin{array}{l}\text { 能进入全国比 } \\
\text { 赛前十二名、 } \\
\text { 全省前六名 }\end{array}$ & $\begin{array}{c}0.55 \\
(0.5-0.6)\end{array}$ \\
\hline & 中下 & $\begin{array}{c}\text { 无具体校领导 } \\
\text { 管; 缺乏会议监 } \\
\text { 督, 不能较好解 } \\
\\
\text { 决问题 }\end{array}$ & $\begin{array}{c}\text { 有支持, 但不 } \\
\text { 能到位 }\end{array}$ & $\begin{array}{c}\text { 责任分工不 } \\
\text { 甚到位 }\end{array}$ & $\begin{array}{c}\text { 不完全、不完 } \\
\text { 整 }\end{array}$ & $\begin{array}{c}\text { 缺乏科学的 } \\
\text { 合理性 }\end{array}$ & $\begin{array}{l}\text { 不够科学、严 } \\
\text { 谨, 计划不周 }\end{array}$ & 不够好 & $\begin{array}{c}\text { 效果不理 } \\
\text { 想 }\end{array}$ & $\begin{array}{c}\text { 学习效率 } \\
\text { 不好 }\end{array}$ & $\begin{array}{c}\text { 能进入全省前 } \\
\text { 八名 }\end{array}$ & $\begin{array}{c}0.35 \\
(0.3-0.4)\end{array}$ \\
\hline & 下 & $\begin{array}{c}\text { 没有校领导管 } \\
\text { 理; 无会议制度; } \\
\text { 完全不能解决相 } \\
\text { 关问题 }\end{array}$ & 不能支持 & $\begin{array}{c}\text { 无责任分工、 } \\
\text { 混乱 }\end{array}$ & $\begin{array}{c}\text { 没有管理, 无 } \\
\text { 章法 }\end{array}$ & $\begin{array}{l}\text { 没有相应手 } \\
\text { 段方法标准 } \\
\text { 凭经验办事 }\end{array}$ & 不科学不严谨 & 效果差 & 无力度 & \begin{tabular}{|c|} 
无任何效 \\
率, 学习跟 \\
不上
\end{tabular} & $\begin{array}{c}\text { 在全省前十名 } \\
\text { 之后 }\end{array}$ & $\begin{array}{c}0.15 \\
(0.1-0.2)\end{array}$ \\
\hline \multicolumn{2}{|c|}{$\begin{array}{c}\text { 各指标 } \\
\text { 权重系数 }\end{array}$} & 0.12 & 0.08 & 0.07 & 0.08 & 0.14 & 0.10 & 0.11 & 0.07 & 0.08 & 0.15 & 总体 1 \\
\hline
\end{tabular}




\section{2 操作}

聘请十位专家组成评价组（其中由主管领导、量化专 家、运动队代表组成)。

各位专家参依评价表（表 1) 对本例某高校所建高水 平运动队进行评价, 其中（表 2) 经第一位专家评议该被 评高校高水平运动队, 各项指标得分为 (见表 2):

\begin{tabular}{|l|l|l|l|l|l|l|l|l|l|}
\hline 1 & 2 & 3 & 4 & 5 & 6 & 7 & 8 & 9 & 10 \\
\hline 上 & 中上 & 上 & 上 & 中上 & 中上 & 中 & 中上 & 中上 & 中上 \\
\hline
\end{tabular}

代入计算公式: $F_{i}=\left(\sum A_{i} \times Z_{i}\right) \times 100$ (其中 $F_{i}$ 为 某一位专家评分; $A_{i}$ 为各指标权重值; $Z_{i}$ 为隶属度值; 100 为化成标准百分）

$$
\text { 则 } \begin{aligned}
F_{i}= & (0.12 \times 0.95+0.08 \times 0.75+0.07 \times 0.95 \\
& +0.08 \times 0.95+0.14 \times 0.75+0.10 \times 0.75 \\
& +0.11 \times 0.55+0.07 \times 0.75+0.08 \times 0.75 \\
& +0.15 \times 0.75) \times 100 \\
= & (0.114+0.06+0.067+0.076+0.105+0.075 \\
& +0.061+0.053+0.06+0.113) \times 100 \\
= & 0.784 \times 100 \\
= & 78.4 \text { (分) }
\end{aligned}
$$

以上仅为其一名专家所评得分，其余 9 名专家对该高 水平运动队所评得分 (经以上相同方法计算所得):

$79.8 ; 82.1 ; 80.8 ; 84.2 ; 78.6 ; 83.4 ; 81.6 ; 78.8 ; 82.3$

则最后评分 计算公式: $F_{N}=\sum F_{i} / N$ (其中 $F_{N}$ 为所有专 家评分的最后平均值）

$$
\text { 则 } \begin{aligned}
F_{N}= & 78.4+79.8+82.1+80.8+84.2+78.6 \\
& +83.4+81.6+78.8+82.3) \div 10 \\
= & 810 \div 10 \\
= & 81 \text { (分) }
\end{aligned}
$$

对照综合评分等级划分表 (见表 3 ):

\section{表 C 等级划分表}

\begin{tabular}{|c|c|}
\hline 成绩（分） & 等级 \\
\hline $85.4-100$ & 上等（优） \\
\hline $70.8-85.3$ & 中上等（良） \\
\hline $61.8-70.7$ & 中等 (中) \\
\hline $50-61.7$ & 中下等（差） \\
\hline $0-49.9$ & 下等 (劣) \\
\hline
\end{tabular}

该高校经专家组依“Fuzzy 公式法”评价为 81 分 (中上 等)。

\section{3}

应用本方法对所有参评单位（高校）统一由专家组依 据此方法计算出最后有效得分, 再逐一按分数高低顺序排 队（根据黄金分割法— 0.618 , 可取前 $61.8 \%$ 院校剔除后 $38.2 \%$ ，也可取前 $38.2 \%$ 院校剔除后 $61.8 \%$ 院校)，这样合 理取舍就会达到其公平、公正、公开的评价目的了。

\section{4. 结论}

通过以上“Fuzzy 模糊公式综合评价法”的评价分析, 该高校高水平运动队的最后得分为 81 分（处于中上等水 平), 可作为其全面综合评价的有力依据, 也是其建设成果 的客观鉴定。有鉴如此, 还能作为主管部门判断能否继续 搞好高水平运动队建设的合法标准（存在和取消的评价条 件)。

“Fuzzy 模糊公式综合评价法”既科学合理（有信度）、 又简便易行 (有效度), 尤其对具有一定模糊概念性质的事 物指标进行量化评价更为适用。

它不仅对体育教学质量、而且对群体 (全民健身)、运 动训练、竞赛、管理乃至科学研究等的质量评价均有较好 的应用价值和参考意义。

\section{参考文献 (References)}

[1] Jijian Xie and Chengping Liu "Fuzzy mathematics method and its application," Huazhong University of Science and Technology press, August 2006.

[2] Zhandou Fei and Yonglong Zhang "High level sports teams in Colleges and universities present situation investigation and development countermeasure research -- Research on the high level sports team in 7 universities of Anhui Province," Journal of Tonghua Normal University, 2010.2.

[3] Xinzhao You "Construction of high level sports teams in Colleges and universities quality evaluation system," Journal of Jingmen Technical College, 2009.

[4] Chunhong Huang "Difficulties and Countermeasures of the development of high level sports teams in Colleges and Universities," Sports academic world. March 2010. 